\title{
Improved Speed Sensorless Vector Control Algorithm of Induction Motor Based on Long Cable
}

\author{
Yonghong Deng ${ }^{1,2} \cdot$ Zhishan Liang $^{1} \cdot$ Pengcheng Xia $^{1} \cdot$ Xin Zuo $^{1}$
}

Received: 15 June 2018 / Revised: 28 September 2018 / Accepted: 3 October 2018 / Published online: 3 January 2019

(c) The Author(s) 2018

\begin{abstract}
In many applications, especially electrical submersible pump required remote operation of inverter via a long motor cable. The conventional control algorithm of induction motor (IM) didn't operate effectively, which ignored the influence of the cable length, and didn't consider the effect of long cable distribution parameters. A speed sensor technique was also difficult to achieve. In this paper, an improved speed sensorless vector control algorithm (ISSVCA) for IM based on long cable was proposed. Based on the analysis of long cable motor drive system of the inverter, the two-port $\pi$ network model of the long cable was established. The functional relationship between the voltage/current parameters of the two ports of the long cable and the cable distribution parameters was deduced. The function expression was transformed to the $\alpha-\beta$ stationary reference frame, the accurate motor terminal voltage/current was calculated, so that the flux model was constructed to realize the observation of the flux, accurate velocity identification, and closed-loop control of the torque, flux and current. Simulation and experimental results showed that the proposed ISSVCA based on long cable increased the starting electromagnetic torque, decreased speed dip and speed recovery time caused by sudden loads, reduced the DC current harmonics, and had good dynamic and static characteristics.
\end{abstract}

Keywords Speed sensor-less vector control $\cdot$ Long cable $\cdot$ Electrical submersible pump (ESP) $\cdot$ Inverter · Induction motor (IM)

\section{Introduction}

The electric submersible pump (ESP) is an important production device for oil exploitation in deep-sea oil fields, particularly applicated for the fluids that contain minimal amounts of gas [1]. In the actual production of deep-sea oil

Zhishan Liang

1972601365@qq.com

Yonghong Deng

dyhsyjdyx@163.com

Pengcheng Xia

1036132089@qq.com

Xin Zuo

zuox@cup.edu.cn

1 Department of College of Geophysics and Information Engineering, China University of Petroleum-Beijing, Beijing, China

2 Department of School of Electronic Information Engineering, North China Institute of Science and Technology, Langfang, China fields, this device is installed at the bottom of subsea wells up to $7000 \mathrm{~m}$ deep for oil extraction, and is driven by the inverter via long transmission cable of ranging from several kilometers to tens of kilometers [2]. The inverter can control the ESP to a speed well that better producing the well and keeping the ESP within its best efficiency range, it also offers soft motor starting for ESP systems and reduces impact to power grid during the ESP systems start-up [3]. Hence, the inverter is widely used in oil field facilities, some of latest facilities could have up to $80 \%$ loads supplied power by Inverter.

The connection between inverter and the ESP through the long submarine cable incurs some problems [4, 5], mainly long cable distribution parameters [2] which caused changes in the inverter output voltage, current and phase, introduce harmonics into the DC-link current. Moreover, the long cable impedance voltage drop which decreased the starting electromagnetic torque, increases the rise time and causes starting problems, especially in case with high-inertia motor loads [6]. The voltage drop across the long cable impedance increases speed dip and speed recovery time, when sudden load was 
applied. The voltage regulation needs to be increased and the inverter modulation index is apt to be saturated with the increase of the cable length [7]. These problems limit the application of the inverter, which making the various control algorithms of the inverter, especially the vector control algorithm, unable to operate effectively. For speed sensor-less vector control algorithm, the flux and velocity estimation technique are prerequisite $[8,9]$. The observers which are used for IM flux and velocity estimation require the exact motor terminal voltage/current [10]. That direct measuring motor terminal voltage/current signals may be too costly or too difficult to achieve for long motor subsea cable drives due to subsea cable length or safety/environmental precautions. Hence, the motor terminal voltage/current must be calculated from the inverter side.

There are some control algorithms used for remote operation of inverter via a long motor subsea cable, such as the stability controller for open-loop operation which can be used for motor derived with an output filter and transformer in oil pump applications [11], the open loop current regulated sensor-less control scheme for an induction and permanent magnetic motor derived with output sinewave filter and transformer which provides sufficient starting torque with controlled drive/ motor current [12], the robust voltage vector control strategy for a PMSM driving a high-power ESP [13]. These methods are to improve the conventional scalar control algorithm to control the motor drives. However, there is no literature on the research of the speed sensor-less vector control algorithm for IM based on long cable.

In this paper, the ISSVCA, needed for long motor cable, was proposed. The presented ISSVCA was based on the exact long cable model, which was the motor stator voltage and current could be calculated from the inverter output voltage/ current using $\alpha-\beta$ model for the long cable in the stationary reference frame, and the correct command voltage could be given in current control cycle which was based on the state equation of the IM in the synchronous rotating reference frame. An experimental setup was implemented with a $1-\mathrm{km}$ cable model. Practical aspects, such as cable selection and inverter limitations, were considered in the experimental setup to match a scaled-down actual inverter. Simulation in addition to experimental results verified the correctness and effectiveness of the proposed ISSVCA.

This paper is organized into six sections. Following the introduction in Sect. 1, speed sensor-less vector control technique is discussed in Sect. 2. In Sect. 3, the long motor subsea cable model and remote motor voltage/current calculator are illustrated. The proposed ISSVCA for IM is presented in Sect. 4. Simulation and experimental results are illustrated in Sect. 5. Finally, the conclusion forms Sect. 6.

\section{Speed Sensorless Vector Control Technique}

\subsection{IM Model}

The fundamental operation principle of the rotor field-oriented vector control (FOC) [14] is to obtain equivalent $\mathrm{DC}$ motor model in a synchronous rotating reference frame through an appropriate coordinate transformation. The torque $T_{e}$ and rotor flux $\psi_{r}$ are controlled independently of each other following the control method of the DC motor, and then the control amounts in the synchronous rotating reference frame are inversely transformed to obtain the corresponding amounts of the three-phase coordinate system to implement the control. The motor model after rotor fieldoriented [15] is as follows:

(1) Stator voltage equation

$\left\{\begin{array}{l}u_{s d}=R_{s} i_{s d}+p \sigma L_{s} i_{s d}-\sigma L_{s} \omega_{1} i_{s q}+p \frac{L_{m}}{L_{r}} \psi_{r} \\ u_{s q}=R_{s} i_{s q}+p \sigma L_{s} i_{s q}+\sigma L_{s} \omega_{1} i_{s d}+\frac{L_{m}}{L_{r}} \omega_{1} \psi_{r}\end{array}\right.$

where $u_{s d}, u_{s q}$ are motor stator voltage components in the $d-q$ rotating reference frame $(\mathrm{V}) . i_{s d}, i_{s q}$ are motor stator current components in the $d-q$ rotating reference frame (A). $R_{s}, p, \sigma, L_{s}, \omega_{1}, L_{r}, L_{m}, \psi_{r}$ are motor stator resistance $(\Omega)$, differential operator, leakage coefficient, motor stator inductance $(\mathrm{H})$, synchronous angular velocity $(\mathrm{r} / \mathrm{min})$, motor rotor inductance $(\mathrm{H})$, motor mutual inductance $(\mathrm{H})$, motor rotor flux linkage amplitude, respectively.

(2) Torque equation

$T_{e}=\frac{3 n_{p} L_{m}}{2 L_{r}} \psi_{r} i_{s q}$

where $n_{p}, T_{e}$ are motor number of pole pairs, motor developed torque $(\mathrm{N} \mathrm{m})$, respectively.

(3) Decoupled voltage equation

$\left\{\begin{array}{l}u_{s d}^{* *}=-\omega_{1} \sigma L_{s} i_{s q}^{*} \\ u_{s q}^{* *}=\omega_{1} \sigma L_{s} i_{s d}^{*}+\omega_{1} \frac{L_{m}}{L_{r}} \psi_{r}^{*}\end{array}\right.$

$\omega_{1}=p \theta$

where $u_{s d}^{* *}, u_{s q}^{* *}$ are coupling voltages $(\mathrm{V}) . i_{s d}^{*}, i_{s q}^{*}$ are motor stator reference current components in the $d-q$ rotating reference frame (A). $\psi_{r}^{*}, \theta$ are motor rotor reference flux linkage amplitude, rotor flux phase angle, respectively. 


\subsection{The Model Reference Adaptive System Based on Rotor Flux}

The model reference adaptive system (MRAS) [16] based on rotor flux, which is using the voltage model as a reference model and using the current model as an adjustable model. The error from cross multiplication of the voltage and current model outputs is used to generate the estimated speed using a PI controller. The system equations are as follows:

(1) Stator model (reference model)

$\left\{\begin{array}{l}\psi_{\mathrm{r} \alpha}=\frac{L_{r}}{L_{m}}\left[\int\left(u_{s \alpha}-R_{s} i_{s \alpha}\right) d t-\sigma L_{s} i_{s \alpha}\right] \\ \psi_{\mathrm{r} \beta}=\frac{L_{r}}{L_{m}}\left[\int\left(u_{s \beta}-R_{s} i_{s \beta}\right) d t-\sigma L_{s} i_{s \beta}\right]\end{array}\right.$

$\psi_{\mathrm{r}}=\sqrt{\psi_{r \alpha}^{2}+\psi_{r \beta}^{2}}$

$\theta=\sin ^{-1} \frac{\psi_{\mathrm{r} \beta}}{\psi_{\mathrm{r} \alpha}}$

where $\psi_{r \alpha}, \psi_{r \beta}$ are motor rotor flux linkage components in the $\alpha-\beta$ stationary reference frame (Wb). $u_{s \alpha}, u_{s \beta}$ are motor stator voltage components in the $\alpha-\beta$ stationary reference frame $(\mathrm{V}) . i_{s \alpha}, i_{s \beta}$ are motor stator current components in the $\alpha-\beta$ stationary reference frame (A).

(2) Rotor model (adjusted model)

$\left\{\begin{array}{l}\psi_{\mathrm{ra}}^{r}=\int\left(-\frac{R_{r}}{L_{r}} \psi_{\mathrm{ra}}^{r}-\omega \psi_{\mathrm{r} \beta}^{r}+L_{m} \frac{R_{r}}{L_{r}} i_{s \alpha}\right) d t \\ \psi_{\mathrm{r} \beta}^{r}=\int\left(-\frac{R_{r}}{L_{r}} \psi_{\mathrm{r} \beta}^{r}+\omega \psi_{\mathrm{ra}}^{r}+L_{m} \frac{R_{r}}{L_{r}} i_{s \beta}\right) d t\end{array}\right.$

where $\psi_{r \alpha}^{r}, \psi_{r \beta}^{r}$ are motor rotor flux linkage components in the $\alpha-\beta$ stationary reference frame (generated from a rotor model based on the estimated speed)(Wb). $\omega, R_{r}$ are estimate motor angular speed $(\mathrm{r} / \mathrm{min})$, motor rotor resistance $(\Omega)$, respectively.

(3) Error equation

$\mathrm{e}_{\mathrm{speed}}=\psi_{\mathrm{r} \beta} \psi_{\mathrm{ra}}^{\mathrm{r}}-\psi_{\mathrm{r} \alpha} \psi_{\mathrm{r} \beta}^{\mathrm{r}}$.

(4) Estimated speed calculation

$\omega=\left(K_{p_{-} e s t}+\frac{K_{i \_s t}}{s}\right) e_{\text {speed }}$

where $\mathrm{K}_{\mathrm{p} \_ \text {est }}, \mathrm{K}_{\mathrm{i} \_ \text {est }}$ are motor speed PI controller constants, respectively.

Figure 1 shows the control block diagram of feed-forward decoupling and motor stator voltages generated unit [15], where the coupling voltages $u_{s d}^{* *}$ and $u_{s q}^{* *}$ are generated according to the given motor stator d-axis current

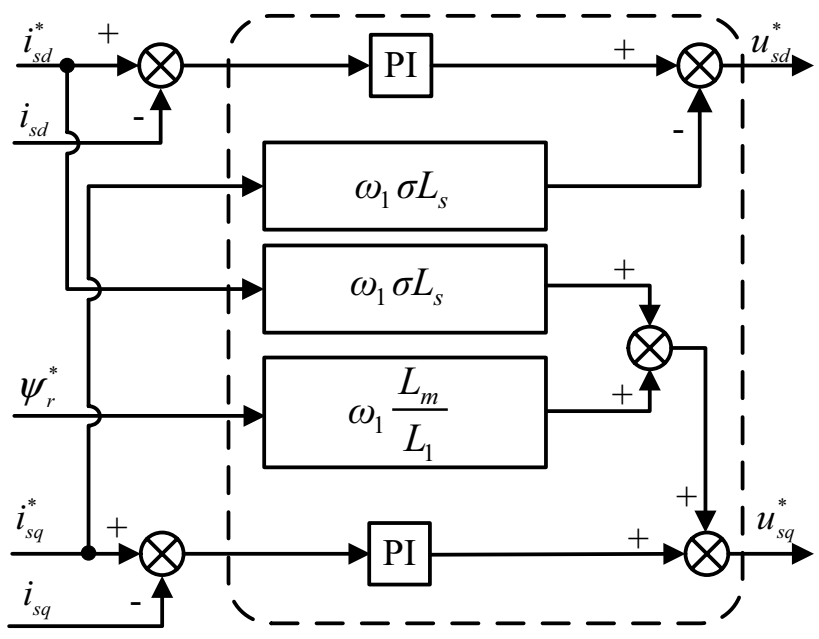

Fig. 1 Feed-forward decoupling and motor stator voltages generated unit

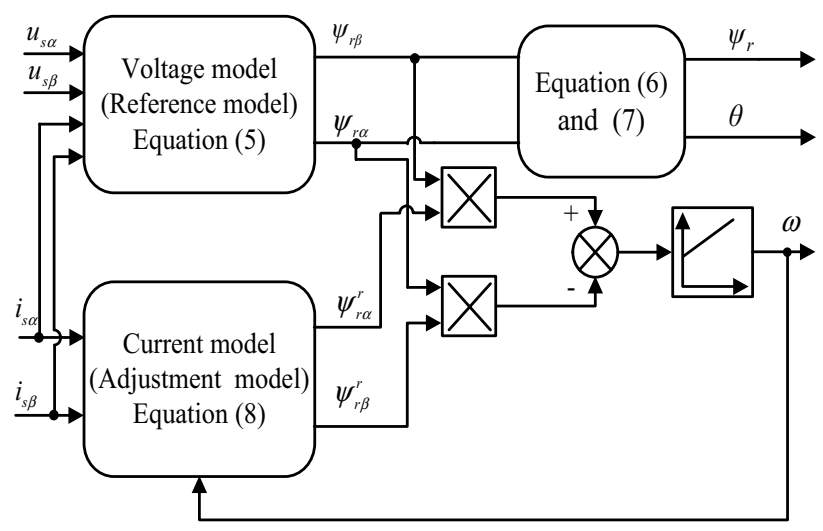

Fig. 2 MRAS-based speed estimation and flux calculation unit

component $i_{s d}^{*}$, q-axis current component $i_{s q}^{*}$, and rotor flux linkage $\psi_{r}^{*}$. Figure 2 shows the block diagram for MRASbased speed estimation and flux calculation, where the estimated rotor angular speed $\omega$, rotor flux linkage amplitude $\psi_{r}$ and the rotor phase angle $\theta$ are calculated from the measured the motor voltage/current signals. The estimated motor speed, flux linkage amplitude and rotor phase angle are used in the ISSVCA as shown in the following sections.

Figure 3 shows the conventional speed sensor-less vector control algorithm (CSSVCA) [17, 18] of IM based on long cable. This algorithm is a speed closed-loop control system. The aims are to achieve speed estimation, torque and flux decoupling through coordinate transformation, flux and speed observers. These give independent control of the flux and torque during both the steady state and dynamic condition. 


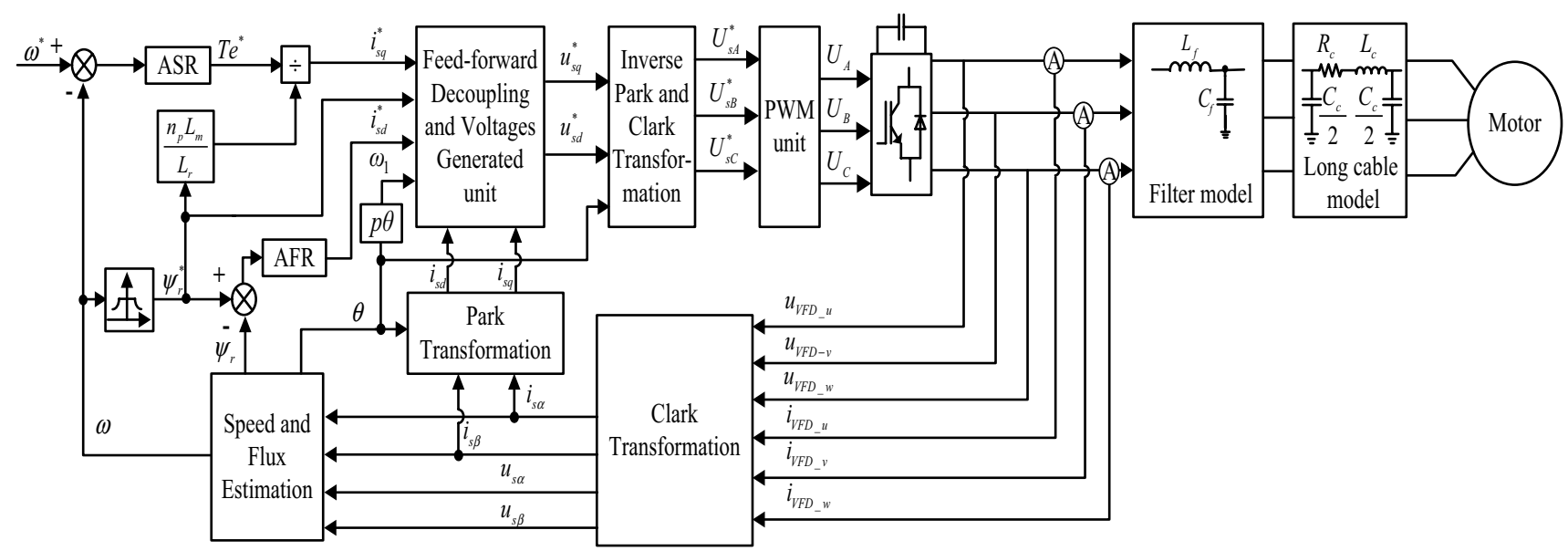

Fig. 3 Conventional speed sensorless vector control algorithm of IM based on long cable

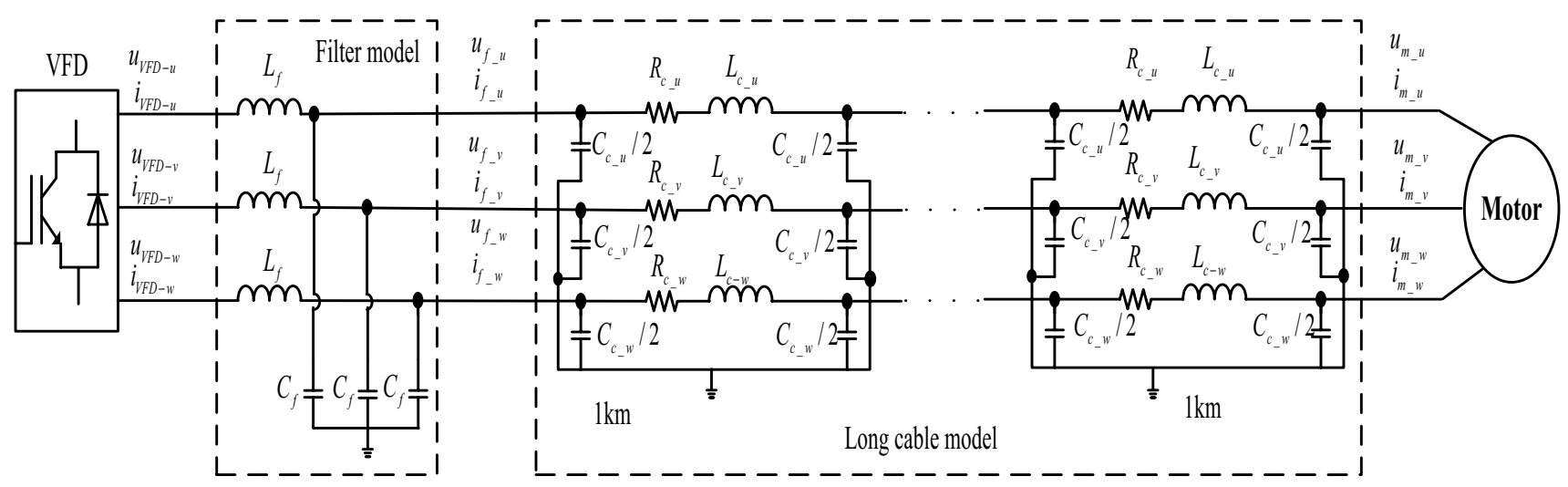

Fig. 4 Long cable and filter $\pi$ network model of inverter induction motor drive system

\section{Long Cable Modeling and Calculation of Motor Stator Voltage and Phase Current}

The analysis of the problems associated with long motor cable drives needs reliable modeling of the complete drive system, especially the long subsea cable. Where frequencydomain analysis is a powerful tool in long cable modeling [19]. Lumped R, L and C elements can represent the long cable effectively, even for transient analysis. Applying this modeling technique is simple and does not reduce the accuracy [20-22], this model is sufficient to give accurate results on long motor cable terminations [5]. Therefore, in this paper, a $\pi$-network with lumped elements $\mathrm{R}, \mathrm{L}$ and $\mathrm{C}$ was used to model the long motor cable and output filter. Figure 4 shows the long cable and filter $\pi$-network model of inverter IM drive system. The simulated long motor cable was a subsea umbilical, which was also a PWM special insulation. Table 1 lists the parameters of this long cable.
Table 1 Cable parameters

\begin{tabular}{lll}
\hline Quantity & Value & Unit \\
\hline Cable & 2XS(FL)2YRAA 6/10(12) kV & - \\
Resistance & 0.34 & $\Omega / \mathrm{km}$ \\
Inductance & 0.38 & $\mathrm{mH} / \mathrm{km}$ \\
Capacitance & 0.29 & $\mu \mathrm{F} / \mathrm{km}$ \\
\hline
\end{tabular}

The two-port $\pi$ network model can be used to represent each phase model of the sinewave filter and long cable. Figure 5 a shows the sinewave filter two-port impedance $\pi$ network model. Figure 6a shows the long cable two-port impedance $\pi$-network model. As a balanced three-phase network [23, 24], the each phase parameters of the sinewave filter model and long cable model shown in Fig. 4 are equal, and can be transformed to the $\alpha-\beta$ stationary reference frame as shown in Figs. $5 b, c$ and $6 b$, c. There are: 


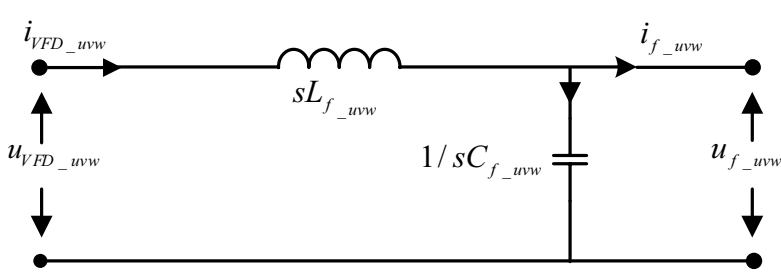

(a) sinewave filter two-port network representation.

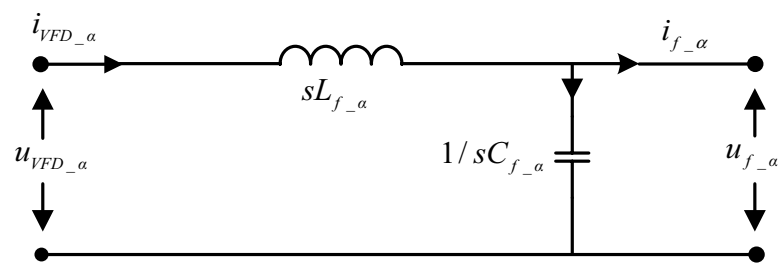

(b) Sinewave filter $\alpha$-axis network model in the stationary reference frame

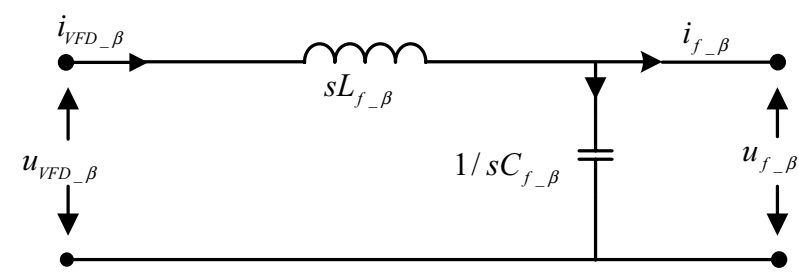

(c) Sinewave filter $\beta$-axis network model in the stationary reference frame

Fig. 5 Sinewave filter $\pi$-network model

$L_{f_{\_} \alpha}=L_{f_{\_} \beta}=L_{f_{\_} u}=L_{f_{-} v}=L_{f_{-} w}=L_{f}$

$C_{f_{-} \alpha}=C_{f_{-} \beta}=C_{f_{-} u}=C_{f_{-} v}=C_{f_{-} w}=C_{f}$

$R_{c \_\alpha}=R_{c \_\beta}=R_{c \_u}=R_{c_{-} v}=R_{c \_w}=R_{c}$

$L_{c \_\alpha}=L_{c \_\beta}=L_{c \_u}=L_{c \_v}=L_{c_{-} w}=L_{c}$

$C_{c_{-} \alpha}=C_{c_{-} \beta}=C_{c_{\_} u}=C_{c_{-} v}=C_{c_{-} w}=C_{c}$

where $L_{f_{-} \alpha}, L_{f_{-} \beta}$ are filter inductances per phase in the $\alpha-\beta$ stationary reference frame $(\mathrm{H}) . L_{f_{-} u}, L_{f_{-} v}, L_{f_{-} w}$ are filter inductances per phase (H). $C_{f_{-} \alpha}, C_{f_{-} \beta}$ are filter capacitances per phase in the $\alpha-\beta$ stationary reference frame (F). $C_{f_{-} u}, C_{f_{-} v}, C_{f_{-} w}$ are filter capacitances per phase (F). $R_{c_{-} \alpha}, R_{c_{-} \beta}$ are cable resistances per phase in the $\alpha-\beta$ stationary reference frame $(\Omega) . R_{c_{-} u}, R_{c_{-} v}, R_{c_{-} w}$ are cable resistances per phase $(\Omega) . L_{c_{-} \alpha}, L_{c_{-} \beta}$ are cable inductances per phase in the $\alpha-\beta$ stationary reference frame $(\mathrm{H}) . L_{c_{-} u}, L_{c_{-} v}, L_{c_{-} w}$ are cable inductances per phase $(\mathrm{H}) . C_{c_{-} \alpha}, C_{c_{-} \beta}$ are cable

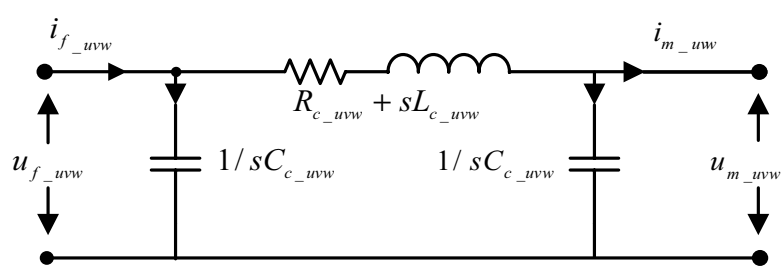

(a) Long cable two-port network representation.

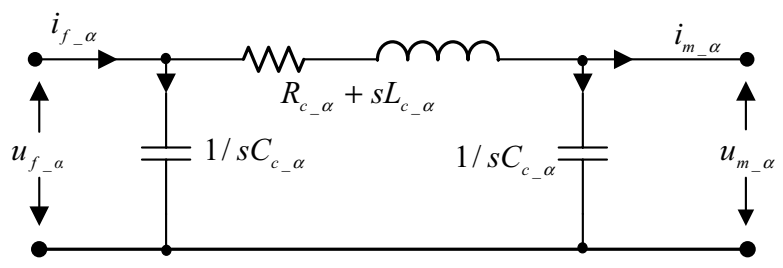

(b) Long cable $\alpha$-axis network model in the stationary reference frame

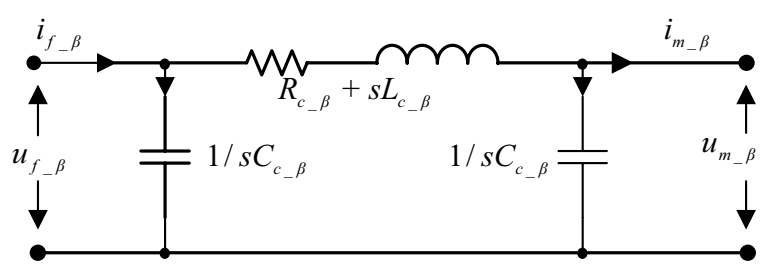

(c) Long cable $\beta$-axis network model in the stationary reference frame

Fig. 6 Long cable $\pi$-network model

capacitances per phase in the $\alpha-\beta$ stationary reference frame $(\mathrm{F})$.

$C_{c_{-} u}, C_{c_{-}}, C_{c_{-} w}$ are cable capacitances per phase (F).

Thanks to the inverter with filter is nearly sinusoidal output, the voltage/current are as well nearly sinusoidal. Figures 5 and 6 show the functional relationship between the voltage/current of the two-port $\pi$-network model and the model distribution parameters. It is not necessary to perform derivative calculation at the fundamental operating frequency, and by replacing the Laplace transform variable s with $j \omega_{1}$, it is solved as the linear equations, without the derivative process, which simplified the calculation. Calculation equation can be expressed by

(1) Sinewave filter parameters function equations at both ends

$\left[\begin{array}{c}u_{f \_u v w} \\ i_{f \_u v w}\end{array}\right]=\left[\begin{array}{cc}1 & -Z_{F} \\ -\frac{1}{Z_{R}} & 1+\frac{Z_{F}}{Z_{R}}\end{array}\right]\left[\begin{array}{c}u_{V F D \_u v w} \\ i_{V F D \_u v w}\end{array}\right]$ 


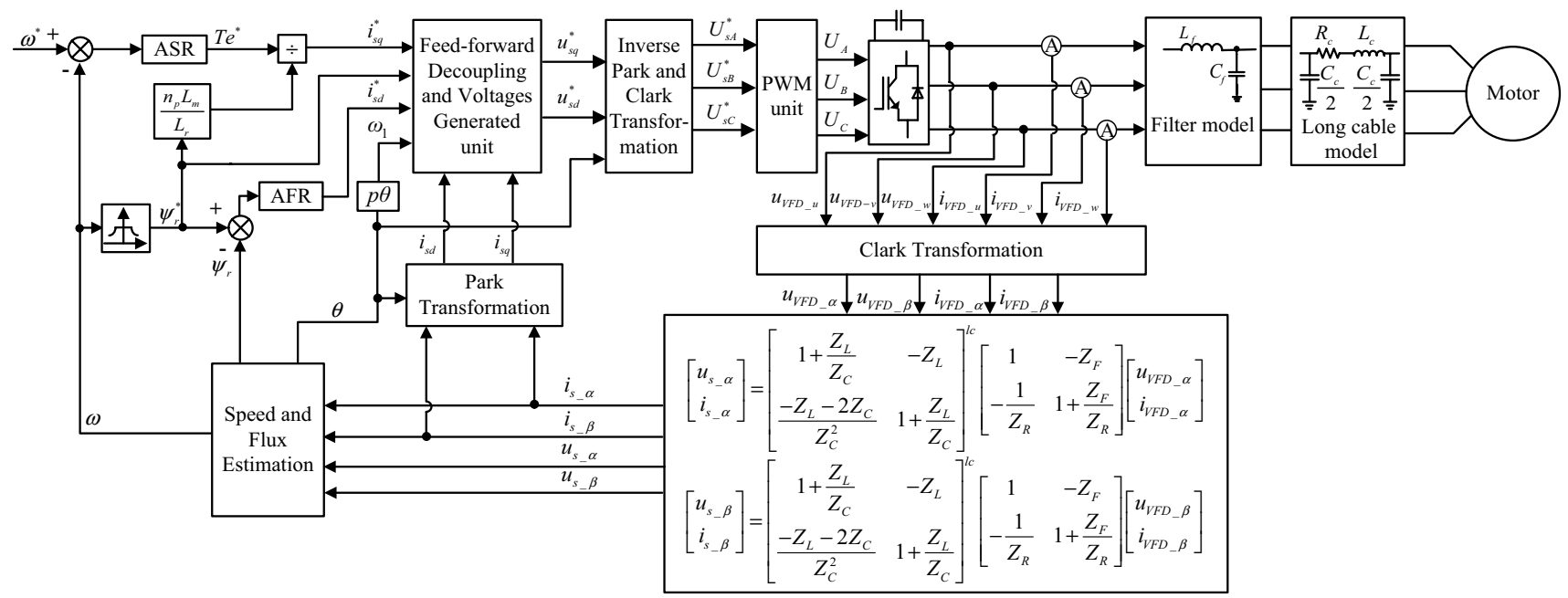

Fig. 7 ISSVCA of IM based on long cable

where

$Z_{F}=j \omega_{1} L_{f}$

$Z_{R}=\frac{1}{j \omega_{1} C_{f}}$

where $u_{f \_u v w}, i_{f \_u v w}, u_{V F D \_u v w}, i_{V F D \_u v w}$ are filter output threephase voltage, filter output three-phase current, inverter output three-phase voltage, and inverter output three-phase current, respectively.

(2) Long cable parameters function equations at both ends

$\left[\begin{array}{c}u_{m \_u v w} \\ i_{m \_u v w}\end{array}\right]=\left[\begin{array}{cc}1+\frac{Z_{L}}{Z_{C}} & -Z_{L} \\ \frac{-Z_{L}-2 Z_{C}}{Z_{C}^{2}} & 1+\frac{Z_{L}}{Z_{C}}\end{array}\right]^{l_{c}}\left[\begin{array}{c}u_{f \_u v w} \\ i_{f \_u v w}\end{array}\right]$

where

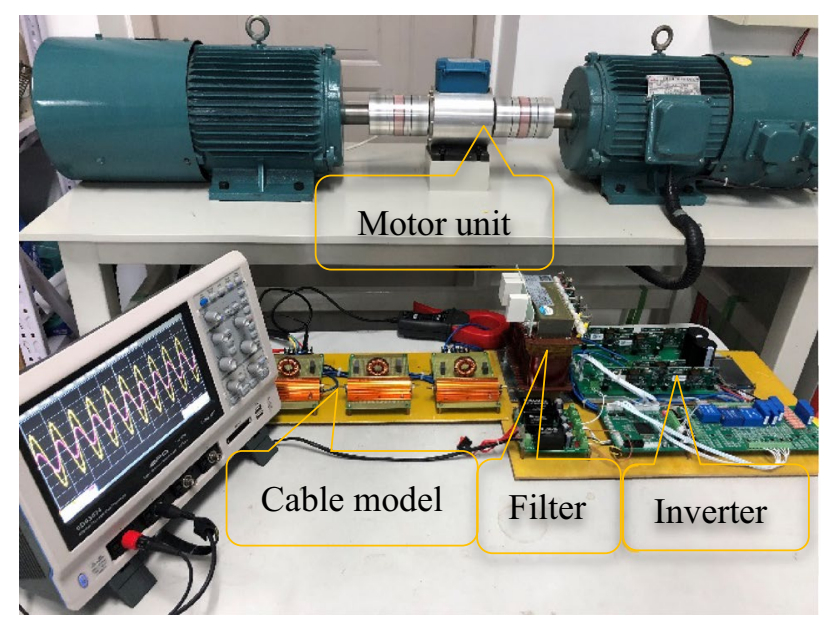

Fig. 8 Experimental setup
Table 2 IM parameters

\begin{tabular}{lll}
\hline Parameter & Value & Unit \\
\hline Rated power & 2.2 & $\mathrm{~kW}$ \\
Poles & 4 & \\
Rated voltage & AC380 & $\mathrm{V}$ \\
Rated current & 5.1 & $\mathrm{~A}$ \\
Rated frequency & 50 & $\mathrm{~Hz}$ \\
Rated speed & 1460 & $\mathrm{rpm}$ \\
Stator resistance & 2.706 & $\Omega$ \\
Rotor resistance & 1.543 & $\Omega$ \\
Mutual inductance & 245 & $\mathrm{mH}$ \\
Rotor inductance & 10.11 & $\mathrm{mH}$ \\
Stator inductance & 10.11 & $\mathrm{mH}$ \\
\hline
\end{tabular}

Table 3 Sinewave filter parameters

\begin{tabular}{lll}
\hline Parameter & Value & Unit \\
\hline Inductance & 4.5 & $\mathrm{mH}$ \\
Capacitance & 2 & $\mu \mathrm{F}$ \\
\hline
\end{tabular}

$Z_{L}=R_{C}+j \omega_{1} L_{C}$

$Z_{C}=\frac{1}{j \omega_{1} C_{C}}$

where $u_{m \_u v w}, i_{m \_u v w}, l_{c}$ are motor three-phase voltage, motor three-phase current, and cable length $(\mathrm{km})$, respectively.

The inductive reactance and capacitive reactance of the unit length $(\mathrm{km})$ of the cable are given by (20) and (21). For different cable lengths $\left(l_{c}\right)$, by putting $l_{c}$ into (19), the functional relationship values between the parameters at both ends of this cable length can be calculate. 

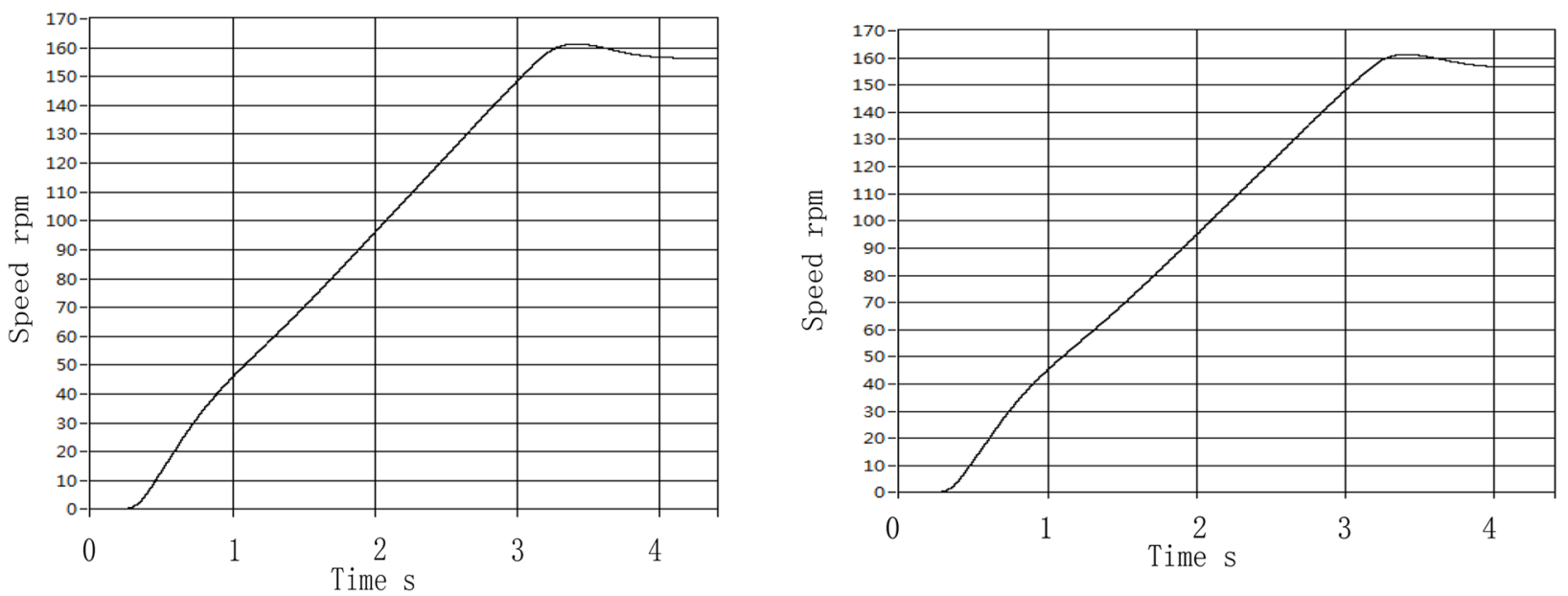

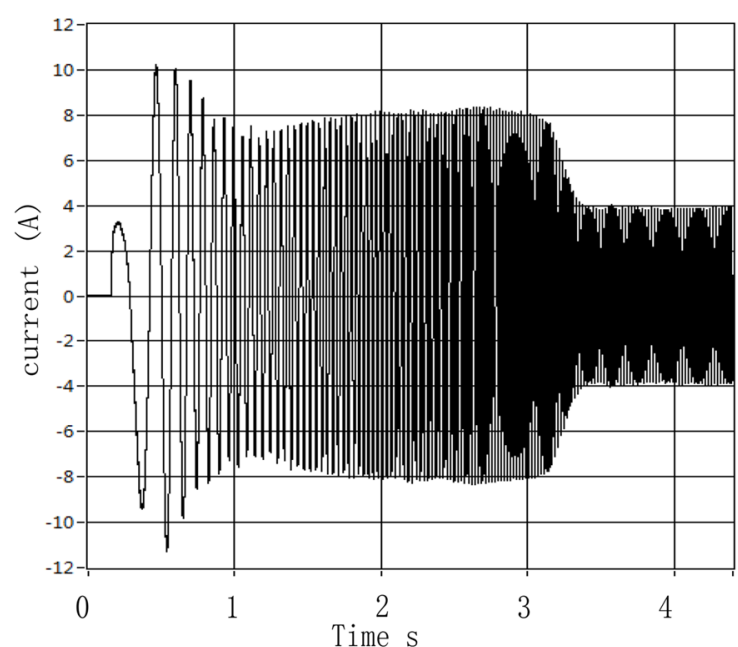

(a) Simulation no-load start waveforms for motor speed and current with the CSSVCA

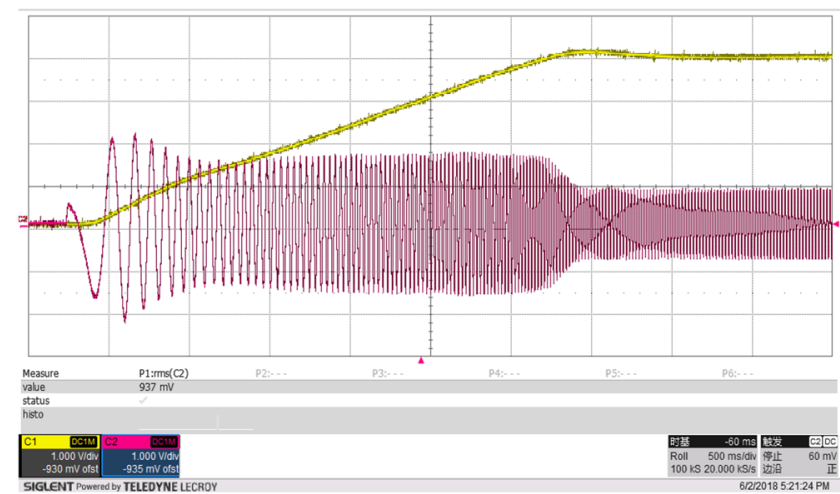

[365rpm/div, 5A/div, 500ms/div]

(c) Experimental no-load start waveforms for motor speed and current with the CSSVCA

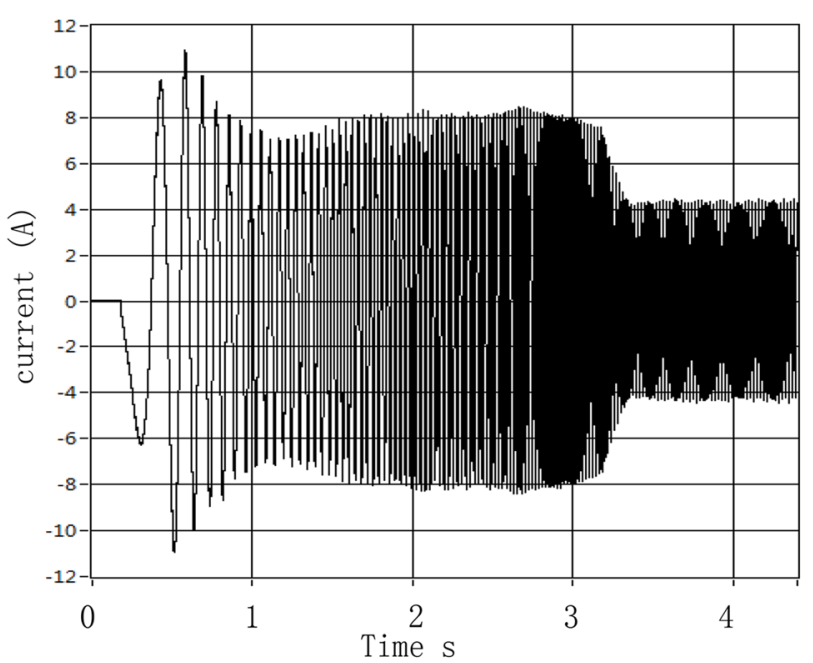

(b) Simulation no-load start waveforms for motor speed and current with the ISSVCA

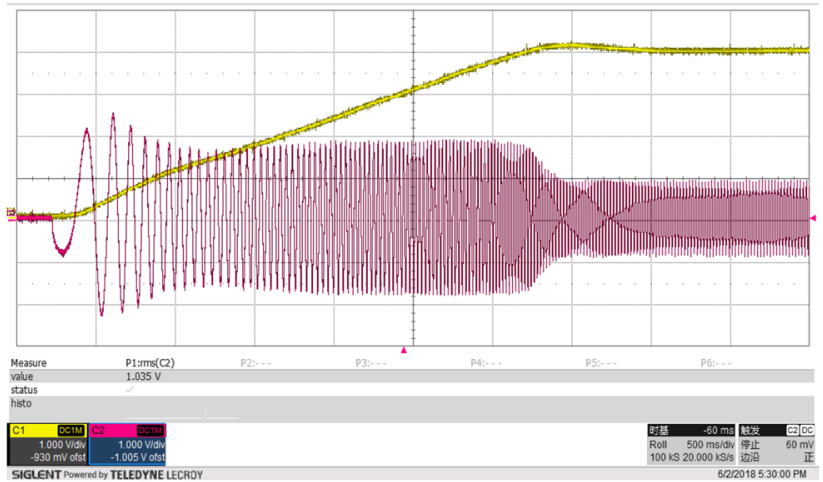

[365rpm/div, 5A/div, 500ms/div]

(d) Experimental no-load start waveforms for motor speed and current with the ISSVCA

Fig. 9 Simulation and experimental no-load response results for motor speed and current with a $1 \mathrm{~km}$ cable 


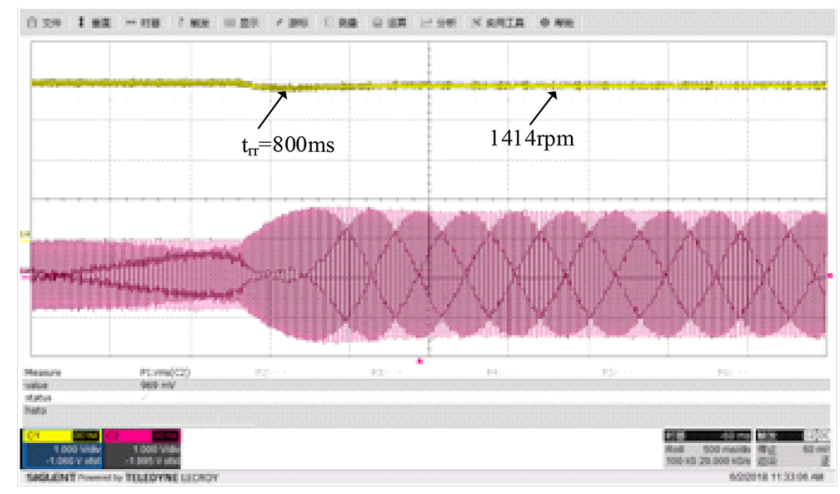

[365rpm/div, 5A/div, 500ms/div]

(a) Experimental sudden load response waveforms for motor speed and current with the CSSVCA

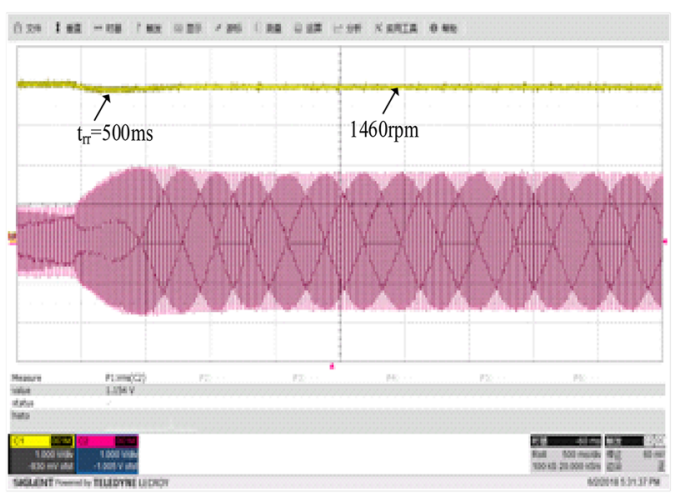

[365rpm/div, 5A/div, 500ms/div]

(b) Experimental sudden load response waveforms

for motor speed and current with the ISSVCA

Fig. 10 Experimental sudden load response results for motor speed and current with a $1 \mathrm{~km}$ cable

By putting (16) into (19), the functional relationship between voltage/current of the motor terminal and output voltage/current of the inverter can be derived as

$\left[\begin{array}{c}u_{m \_u v w} \\ i_{m_{-} \_v w}\end{array}\right]=\left[\begin{array}{cc}1+\frac{Z_{L}}{Z_{C}} & -Z_{L} \\ \frac{-Z_{L}-2 Z_{C}}{Z_{C}^{2}} & 1+\frac{Z_{L}}{Z_{C}}\end{array}\right]^{l_{c}}\left[\begin{array}{cc}1 & -Z_{F} \\ -\frac{1}{Z_{R}} & 1+\frac{Z_{F}}{Z_{R}}\end{array}\right]\left[\begin{array}{c}u_{V F D \_u v w} \\ i_{V F D \_u v w}\end{array}\right]$.

The equations in the $\alpha-\beta$ stationary reference frame are expressed as

$\left[\begin{array}{c}u_{S_{-} \alpha} \\ i_{s_{-} \alpha}\end{array}\right]=\left[\begin{array}{cc}1+\frac{Z_{L}}{Z_{C}} & -Z_{L} \\ \frac{-Z_{L}-2 Z_{C}}{Z_{C}^{2}} & 1+\frac{Z_{L}}{Z_{C}}\end{array}\right]^{l_{c}}\left[\begin{array}{cc}1 & -Z_{F} \\ -\frac{1}{Z_{R}} & 1+\frac{Z_{F}}{Z_{R}}\end{array}\right]\left[\begin{array}{c}u_{V F D \_\alpha} \\ i_{V F D \_} \alpha\end{array}\right]$

$\left[\begin{array}{c}u_{S_{-} \beta} \\ i_{S_{-} \beta}\end{array}\right]=\left[\begin{array}{cc}1+\frac{Z_{L}}{Z_{C}} & -Z_{L} \\ \frac{-Z_{L}-2 Z_{C}}{Z_{C}^{2}} & 1+\frac{Z_{L}}{Z_{C}}\end{array}\right]^{l_{c}}\left[\begin{array}{cc}1 & -Z_{F} \\ -\frac{1}{Z_{R}} & 1+\frac{Z_{F}}{Z_{R}}\end{array}\right]\left[\begin{array}{c}u_{V F D \_\beta} \\ i_{V F D \_\beta}\end{array}\right]$

where $u_{s_{-} \alpha}, u_{s_{-} \beta}$ are calculated motor voltage components from the inverter output voltage/current using a $\alpha-\beta$ model for the long cable in the stationary reference frame (V). $i_{s_{-} \alpha}, i_{s_{-} \beta}$ are calculated motor current components from the inverter output voltage/current using a $\alpha-\beta$ model for the long cable in the stationary reference frame (A). $u_{V F D_{\_} \alpha}, u_{V F D_{-} \beta}$ are inverter voltage components in the $\alpha-\beta$ stationary reference frame $(\mathrm{V}) . i_{V F D_{-} \alpha}, i_{V F D_{-} \beta}$ are inverter current components in the $\alpha-\beta$ stationary reference frame (A).

The actual motor terminal voltage and current can be calculated from the inverter side by (23) and (24).

\section{ISSVCA of IM Based on Long Cable}

The proposed ISSVCA was designed for a motor drive with long cable connection, which was commonly utilized for ESP drives, and the block diagram of algorithm is shown in Fig. 7. The proposed technique was capable of calculating the motor terminal voltage and current from the inverter output voltage/ current signals using a $\alpha-\beta$ model for the long cable in the stationary reference frame. The exact motor terminal voltage/ current were calculated to estimate rotor angular speed, rotor flux amplitude and rotor flux phase angle, instead of directly using the measured inverter output voltage/current signals. So that the accurate rotor flux linkage model was constructed to realize the observation of the rotor flux, accurate velocity identification, and closed-loop control of the torque, flux and current.

\section{Simulation and Experimental Results}

Computer simulation and experiments were performed with the proposed ISSVCA for IM based on long cable. The experimental setup shown in Fig. 8 was used to emulate an long cable drive system, which typically has an inverter, motor unit, sinewave filer and cable model. The parameters of the three-phase IM and sinewave filter used in simulation and experiments are shown in Tables 2 and 3, and the cable model length is $1 \mathrm{~km}$.

Figure 9 shows simulation and experimental no-load response results for motor speed and current with a $1-\mathrm{km}$ cable. Figure 9a, c show simulation and experimental noload start waveforms for motor speed and current with the 


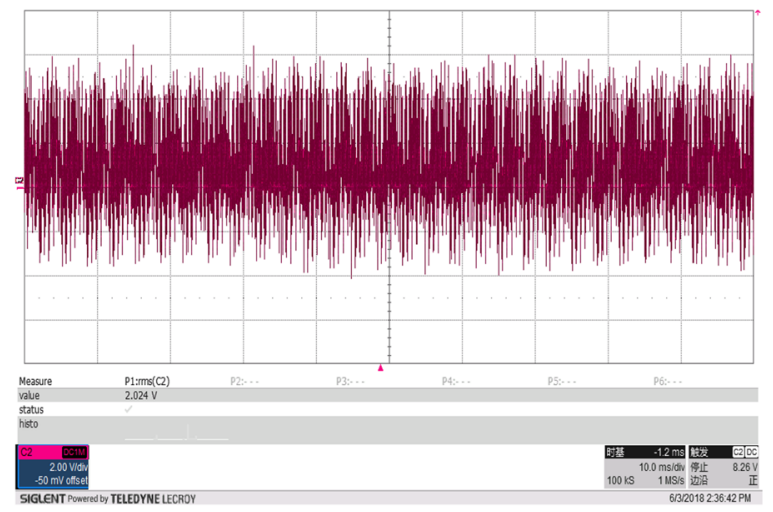

$[1 \mathrm{~A} / \mathrm{div}, 10 \mathrm{~ms} / \mathrm{div}]$

(a) DC-link current experimental no-load waveforms for motor operation with the CSSVCA

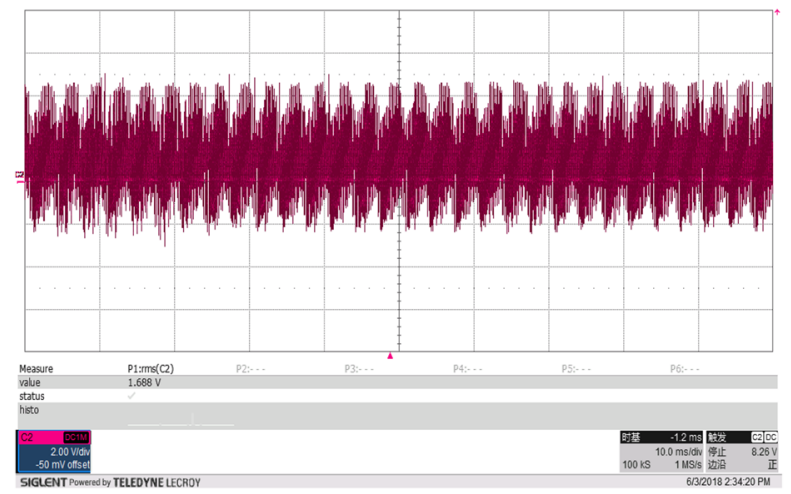

$[1 \mathrm{~A} / \mathrm{div}, 10 \mathrm{~ms} / \mathrm{div}]$

(c) DC-link current experimental no-load waveforms for motor operation with the ISSVCA

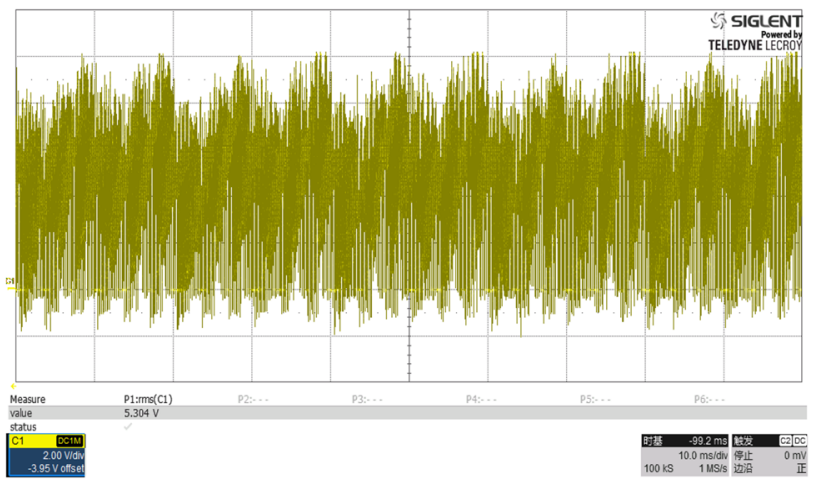

[1A/div, 10ms/div]

(b) DC-link current experimental rated-load waveforms for motor operation with the CSSVCA

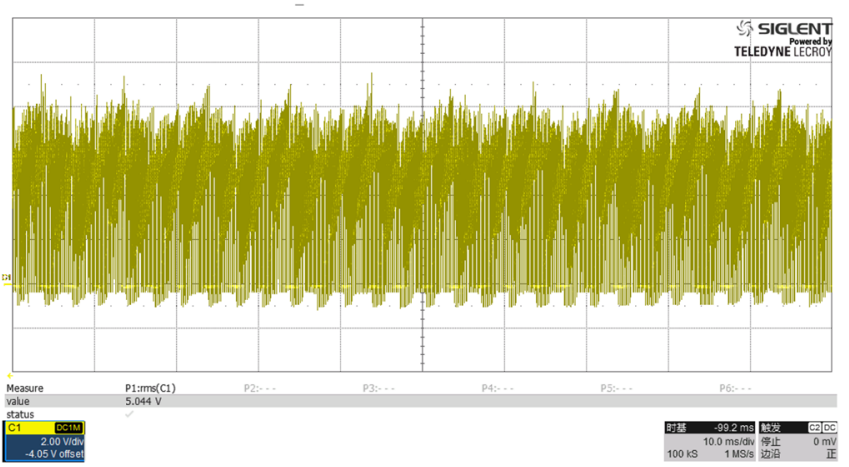

[1A/div, $10 \mathrm{~ms} / \mathrm{div}]$

(d) DC-link current experimental rated-load waveforms for motor operation with the ISSVCA

Fig. 11 DC-link current experimental results for motor operation with a $1 \mathrm{~km}$ cable

CSSVCA. Figure 9b, d show simulation and experimental no-load start waveforms for motor speed and current with the ISSVCA. The motor reaches the rated speed from zero speed in $3 \mathrm{~s}$. The simulation and experimental results in Fig. 9 show that the ISSVCA improves the starting electromagnetic torque and increases the dynamic response.

Figure 10 shows experimental sudden load response results for motor speed and current with a $1-\mathrm{km}$ cable. Figure 10b shows that the ISSVCA enables the motor to restore the speed to $1460 \mathrm{rpm}$ in less than $500 \mathrm{~ms}$, when a sudden rated load is applied. Figure 10a shows that the CSSVCA increases the time to restore the reference speed and causes the speed dip, when the rated load is applied.

Figure 11 shows that the long cable introduces harmonics into the DC-link current as the first element experienced by the inverter is the stray capacitance of the long cable model. This capacitance acts as a short circuit to each inverter voltage pulse. Figure 11 shows that use of the ISSVCA can decrease the harmonics in DC-link current, avoid harmonics in DC-link current which caused problems such as radiated EMI, inaccurate current measurement and false protection system operation, and increase the DC-link capacitor lifetime.

\section{Conclusion}

In this paper, the proposed ISSVCA of IM based on long cable that could be effectively applied to long cable-connected motor loads. This algorithm was fast and accurate in flux and velocity identification, simple in algorithm, less in computation, easy to implement online. 
Simulation and experimental results showed that the ISSVCA could control the reliable and stable operation of the motor, provided sufficient starting electromagnetic torque, and starting current of the motor, made the motor start smoothly, reduced the harmonics in DC-link current, increased the DC-link capacitor lifetime. And it has good dynamic and static characteristics, strong engineering practicality and application promotion value.

Acknowledgements This work are supported by Beijing Natural Science Foundation (no. 3162025), the National Key Research and Development Plan (no. 2016YFC0800103) and "the Fundamental Research Funds for the Central Universities" (no. 3142018049).

OpenAccess This article is distributed under the terms of the Creative Commons Attribution 4.0 International License (http://creativeco mmons.org/licenses/by/4.0/), which permits unrestricted use, distribution, and reproduction in any medium, provided you give appropriate credit to the original author(s) and the source, provide a link to the Creative Commons license, and indicate if changes were made.

\section{References}

1. Chien CH, Bucknall RWG (2007) Analysis of harmonics in subsea power transmission cables used in VSC-HVDC transmission systems operating under steady-state conditions. IEEE Trans Power Deliv 22(4):2489-2497

2. Smochek M, Pollice AF, Rastogi M, Harshman M (2016) Long cable applications from a medium-voltage drives perspective. IEEE Trans Ind Appl 52(1):645-652

3. Liang X, Kar NC, Liu J (2015) Load filter design method for medium-voltage drive applications in electrical submersible pump systems. IEEE Trans Ind Appl 51(3):2017-2029

4. Abu-Rub H, Holtz J, Rodriguez J, Baoming G (2010) Mediumvoltage multilevel converters - state of the art, challenges, and requirements in industrial applications. IEEE Trans Ind Electron 57(8):2581-2596

5. Abdelsalam AK, Masoud MI, Finney SJ, Williams BW (2011) Vector control PWM-VSI induction motor drive with a long motor feeder: performance analysis of line filter networks. IET Electr Power 5(5):443-456

6. Raad RO, Henriksen T, Raphael HB, Hadler-Jacobsen A (1996) Converter-fed subsea motor drives. IEEE Trans 32(5):1069-1079

7. Matheson E, von Jouanne A, Wallace A (1999) Evaluation of inverter and cable losses in adjustable speed drive applications with long motor leads. In: International conference on electric machines and drives, IEMD'99, Seattle, WA, USA, pp 159-161

8. Harnefors L (2001) Design and analysis of general rotor-fluxoriented vector control systems. IEEE Trans Ind Electron 48(2):383-390

9. Rehman H, Derdiyok A, Guven MK, Xu L (2002) A new current model flux observer for wide speed range sensorless control of an induction machine. IEEE Trans Power Electron 17(6):1041-1048

10. Verghese GC, Sanders SR (1988) Observers for flux estimation in induction machines. IEEE Trans Ind Electron 35(1):85-94

11. Liu J, Nondahl TA, Royak S, Rowan TM (2017) Generalized stability control for open-loop operation of motor drives. IEEE Trans Ind Appl 53(3):2517-2525
12. Liu J, Dai J, Royak S, Schmidt P, Alnabi E (2017) Design and implementation of position sensorless starting control in industrial drives with output filter and transformer for oil/pump applications. In: Proceedings of the 32nd IEEE annual applied power electronics specialists conference and exposition (APEC), pp 578-584

13. da Cunha G, Rossa AJ, Alves JA, Cardoso E (2018) Control of permanent magnet synchronous machines for subsea applications. IEEE Trans Ind Appl 54(2):1899-1905

14. Santisteban JA, Stephan RM (2001) Vector control methods for induction machines: an overview. IEEE Trans Educ 44(2):170-175

15. Kawabata Y, Kawakami T, Sasakura Y, Ejiogu EC, Kawabata $\mathrm{T}$ (2004) New design method of decoupling control system for vector controlled induction motor. IEEE Trans Power Electron 19(1):1-9

16. Kumar R, Das S, Syam P (2015) Review on model reference adaptive system for sensorless vector control of induction motor drives. IET Electr Power Appl 9(7):496-511

17. Santisteban JA, Stephan RM (2001) Vector control methods for induction machines: an overview. IEEE Trans Educ 44(2):170-175

18. Cheng Q, Cheng Y, Wang Y, Wang M (2011) Overview of control strategies for AC motor. Power Syst Prot Control 39(9):145-153

19. Amarir S, Al-Haddad K (2008) A modeling technique to analyze the impact of inverter supply voltage and cable length on industrial motor-drives. IEEE Trans Power Electron 23(2):753-762

20. Pomilio JA, de Souza CR, Matias L, Peres PLD, Bonatti IS (1999) Driving AC motors through a long cable: the inverter switching strategy. IEEE Trans Energy Convers 14(4):1441-1447

21. Aoki N, Satoh K, Nabae A (1999) Damping circuit to suppress motor terminal overvoltage and ringing in PWM inverter-fed AC motor drive systems with long motor leads. IEEE Trans Ind Appl 35(5):1014-1020

22. Khodaparast J, Khederzadeh M (2017) Least square and Kalman based methods for dynamic phasor estimation: a review. Prot Control Mod Power Syst 2(2): 1-18

23. Hancock NN (1975) Matrix analysis of electrical machinery. Elsevier, Amsterdam

24. Roostaee S, Thomas MS, Mehfuz S (2017) Experimental studies on impedance based fault location for long transmission lines. Prot Control Mod Power Syst 2(1):16. https://doi.org/10.1186/s4160 1-017-0048-y

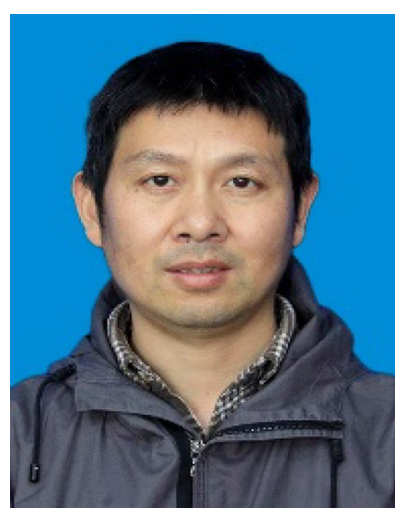

Yonghong Deng received his M.S. degree in the School of Electrical Engineering, Beijing Jiaotong University, Beijing, China in 2005, and is a Ph.D. student in the College of Geophysics and information Engineering, China University of Petroleum-Beijing, Beijing, China. He worked in the School of Electronic Information Engineering, North China Institute of Science and Technology, East Yanjiao, Beijing, China, where he is currently a associate professor. His main research interests 


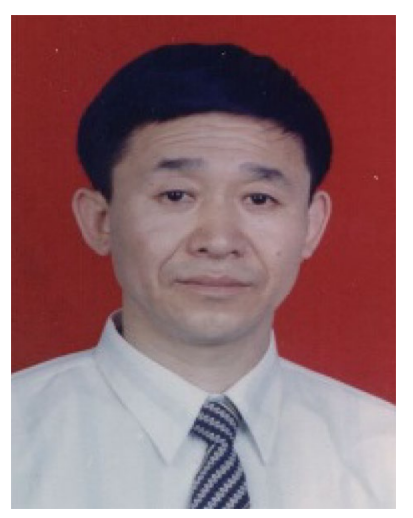

Zhishan Liang received his Ph.D. degree and post-doctor in control theory and control engineering from the College of Information Science and Engineering, Northeast University, Shenyang, China, in 1999 and 2003, respectively. He worked in the College of Geophysics and Information Engineering, China University of Petroleum-Beijing, Beijing, China, where he is currently a professor. From January 2006 to October 2006, he was a visiting scholar in the Department of Electrical Engineering, Lund University, Sweden. His main research interests include nonlinear systems, nonlinear control of electric power system, electrical dehydration, and geo-magnetically induced current effects on oil and gas pipelines.

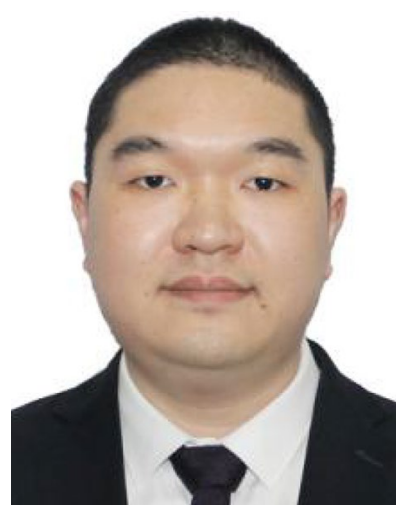

Pengcheng Xia received his B.S. degree in automation from the College of Geophysical and Information Engineering, China University of Petroleum, Beijing, China, in 2012, where he is currently working on a doctorate in control theory and control engineering. His main research interests include fast switching of dual power supply, control theory and application.

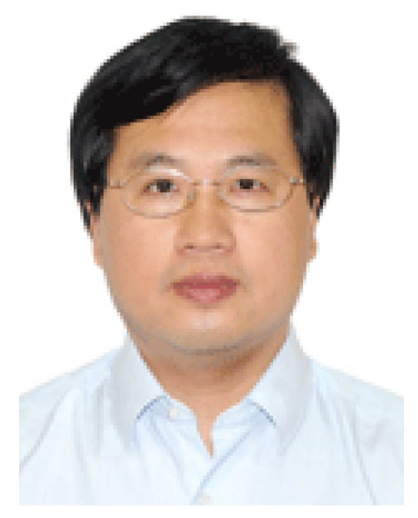

Xin Zuo received his M.S. degree in the control theory and control engineering from Graduate Department, University of Petroleum, Beijing, China, in 1990. From 1990 to 2018, he worked in the College of Geophysical and Information Engineering, China University of Petroleum, Beijing, China, where he is currently a professor and doctoral supervisor. He mainly engaged in the theoretical research and industrial application of the measurement, control and optimization of oil field production, pipeline transportation and petrochemical process. His main research interests include advanced control theory and application, safety protection control system, deep sea oil field automation technology and application. 